\title{
An efficient and recyclable iron(III)-containing imidazolium salt catalyst for cross-coupling of aryl Grignard reagents with alkyl halides
}

\author{
YAN ChunHui, WANG LinLin, GAO HuanHuan, SUN HongMei ${ }^{*} \&$ SHEN Qi ${ }^{*}$ \\ The Key Laboratory of Organic Synthesis of Jiangsu Province, College of Chemistry, Chemical Engineering and Materials Science, Soochow \\ University, Suzhou 215123, China
}

Received April 4, 2011; accepted May 6, 2011; published online February 21, 2012

\begin{abstract}
1,3-Bis(2,6-diisopropylphenyl)imidazolium chloride, [DIPrim]Cl, was used to produce a novel iron(III)-containing imidazolium salt [DIPrim] $\left[\mathrm{FeCl}_{4}\right]$, which included a $N, N$-diarylimidazolium cation $(\mathrm{R}=2,6 \text {-diisopropylphenyl), [DIPrim }]^{+}$, and tetrachloroferrate(III) anion, $\left[\mathrm{FeCl}_{4}\right]^{-}$. This compound was an effective and easy-to-use catalyst for the cross-coupling of aryl Grignard reagents with primary and secondary alkyl halides bearing $\beta$-hydrogens. After simply decanting the cross-coupling product in the ether layer, [DIPrim] $\left[\mathrm{FeCl}_{4}\right]$ could be reused in at least four successive runs without significant loss of catalytic activity.
\end{abstract}

iron(III) complex, imidazolium salt, alkyl halide, cross-coupling, Grignard reagent

Citation: Yan C H, Wang L L, Gao H H, et al. An efficient and recyclable iron(III)-containing imidazolium salt catalyst for cross-coupling of aryl Grignard reagents with alkyl halides. Chin Sci Bull, 2012, 57: 1953-1958, doi: 10.1007/s11434-011-4660-3

The transition metal-catalyzed Grignard cross-coupling reaction is a powerful and widely used method for the construction of carbon-carbon bonds [1]. Although a variety of palladium or nickel-based catalysts are particularly effective for the cross-coupling of alkenyl or aryl halides, recent reports on the use of alkyl halides, especially those with $\beta$ hydrogen atoms, as substrates suggests iron catalysis has potential in this field [2,3]. In comparison with established palladium or nickel-based systems, iron-based catalysts offer a cost efficient, safe and more environmentally benign approach, and the capacity to suppress undesirable $\beta$-hydride eliminations.

To date, a variety of iron-based catalysts have been developed for the cross-coupling of an aryl Grignard reagent with primary or secondary alky halides bearing $\beta$-hydrogens. For example, well-defined iron complexes, such as the iron (II) tetrakisferrate complex [4], iron(III) salen complexes [5], iron(II) or iron(III) imine complexes [6] and iron(III) amine-bis(phenolate) complexes [7], have shown good crosscoupling activity. In addition, although $\mathrm{Fe}(\mathrm{acac})_{3}(\mathrm{acac}=$

*Corresponding authors (email: sunhm@suda.edu.cn; qshen@suda.edu.cn) acetylacetonate) can catalyze this cross-coupling reaction [8], amine additives are necessary to achieve higher yields of the cross-coupled product [9]. Notably, $\mathrm{FeCl}_{3}$ can be used effectively in the presence of appropriate additives, such as amines [9-11], phosphines, phosphites, arsines and carbene precursors [12]. Although the direct use of $\mathrm{FeCl}_{3}$ generally suffers from limitations such as high hygroscopicity of $\mathrm{FeCl}_{3}$ and the variable yield according to the purity and commercial source of $\mathrm{FeCl}_{3}$ [13], this method appears particularly attractive because of the simplicity and low cost of the metal salt combined with the high efficiency of the catalytic system. Consequently, this method represents a very powerful approach, if these limitations can be overcome $[9,11]$.

Two reports describing the use of $\mathrm{FeCl}_{3}$ have appeared in the literature. Cahiez et al. [9] discovered that hygroscopic $\mathrm{FeCl}_{3}$ could be easily modified into a hydrophobic and airstable iron(III) complex $\left.\left[\left(\mathrm{FeCl}_{3}\right)_{2} \text { (tmeda) }\right)_{3}\right]\left(\right.$ tmeda $=N, N, N^{\prime}, N^{\prime}-$ tetramethylethylenediamine) by direct reaction of $\mathrm{FeCl}_{3}$ with tmeda in a 2:3 molar ratio. Moreover, this complex showed significantly better activity than a stoichiometric mixture of $\mathrm{FeCl}_{3}$ and tmeda [10,11]. Of particular note is a 
recent report on the use of 1-butyl-3-methylimidazolium chloride, $[\mathrm{BMim}] \mathrm{Cl}$, instead of the amine ligand to modify $\mathrm{FeCl}_{3}$ to a hydrophobic and air-stable imidazolium salt of iron(III), [BMim] $\left[\mathrm{FeCl}_{4}\right]$ [14]. [BMim] $\left[\mathrm{FeCl}_{4}\right]$ has high activity for the aryl Grignard cross-coupling of alkyl halides, and is a recyclable catalyst. It is also found to be a very efficient catalyst for other organic transformations, such as Friedel-Crafts sulfonylation of aromatics [15], dimerization of 2,5-norbornadiene [16], and glycolysis of poly(ethylene terephthalate) [17]. However, there may be issues with handling and structural definition of the liquid state of this ionic iron(III) complex. In view of this, an alternative easy-to-use, well-defined iron-based catalyst is highly desirable.

Modification of transition metal-based catalysts with imidazolium cations has attracted increasing attention [18]. The use of imidazolium salts as more environmentally benign alternatives to traditional ligands, such as amines and phosphines, provides many advantages over traditional systems in terms of stability, activity, reusability, and low toxicity of the modified catalysts. Thus, imidazolium salts are promising candidates for optimizing synthetic efficiency and addressing green sustainability issues [19].

As a continuation of our work on the development of iron-based catalysts for carbon-carbon bond formation [20], here we report the modification of anhydrous $\mathrm{FeCl}_{3}$ or $\mathrm{FeCl}_{3} \cdot 6 \mathrm{H}_{2} \mathrm{O}$ with 1,3-bis(2,6-diisopropylphenyl)imidazolium chloride, [DIPrim]Cl. This produced a very efficient and easy-to-use iron(III)-containing imidazolium salt [DIPrim]$\left[\mathrm{FeCl}_{4}\right]$ for the cross-coupling of aryl Grignard reagents with primary or secondary alky halides bearing $\beta$-hydrogens.

\section{Experimental}

Since anhydrous $\mathrm{FeCl}_{3}, \mathrm{FeCl}_{3} \cdot 6 \mathrm{H}_{2} \mathrm{O}$ and 1,3-bis(2,6-diisopropylphenyl)imidazolium chloride ([DIPrim]Cl) are hydrophilic, all manipulations were performed under pure argon with rigorous exclusion of air and moisture using standard Schlenk techniques.

\subsection{Materials}

Solvents were distilled from $\mathrm{Na} /$ benzophenone ketyl under pure argon prior to use. Anhydrous $\mathrm{FeCl}_{3}, \mathrm{FeCl}_{3} \cdot 6 \mathrm{H}_{2} \mathrm{O}$ and organic reagents used for the cross-coupling reactions were purchased from Acros Organics (Geel, Belgium), SigmaAldrich (St. Louis, MO), and Alfa Aesar (Ward Hill, MA). Phenylmagnesium bromide was diluted prior to use. [DIPrim] $\mathrm{Cl}$ was prepared by an established method [21].

\subsection{Synthesis}

(i) Synthesis of [DIPrim] $\left[\mathrm{FeCl}_{4}\right]$. Procedure A: A Schlenk flask was charged with [DIPrim]Cl $(2.40 \mathrm{~g}, 5.68 \mathrm{mmol})$, tetrahydrofuran (THF, $20 \mathrm{~mL}$ ) and a stirring bar. To this suspension, $\mathrm{FeCl}_{3}(0.92 \mathrm{~g}, 5.68 \mathrm{mmol})$ in $20 \mathrm{~mL}$ of THF was added. The reaction mixture was stirred for $2 \mathrm{~h}$ at room temperature, filtered, and evaporated to dryness. The residue was recrystallized from THF and hexane to yield yellowgreen crystals $(3.15 \mathrm{~g}, 95 \%)$. Decomposition temperature: 254.1 ${ }^{\circ} \mathrm{C}$. Anal. Calcd for $\mathrm{C}_{27} \mathrm{H}_{37} \mathrm{Cl}_{4} \mathrm{~N}_{2} \mathrm{Fe}$ : C, 55.22; $\mathrm{H}, 6.35$; $\mathrm{N}, 4.77$. Found: C, $54.53 ; \mathrm{H}, 6.27$; N, 4.78. MS (ESI-): $\mathrm{m} / \mathrm{z}$ $197.8097\left[\mathrm{FeCl}_{4}\right]^{-}$(100\%). MS (ESI+): $\mathrm{m} / \mathrm{z} 389.2954$ $\left[\mathrm{C}_{27} \mathrm{H}_{37} \mathrm{~N}_{2}\right]^{+}(100 \%)$. Raman: $335.956 \mathrm{~cm}^{-1}\left(\mathrm{FeCl}_{4}^{-}\right)$.

Procedure B: Following a procedure similar to the synthetic procedure A, a Schlenk flask was charged with [DIPrim]Cl (2.12 g, $5 \mathrm{mmol})$, THF ( $20 \mathrm{~mL})$, and a stirring bar. To this suspension, $\mathrm{FeCl}_{3} \cdot 6 \mathrm{H}_{2} \mathrm{O}(1.35 \mathrm{~g}, 5 \mathrm{mmol})$ in $20 \mathrm{~mL}$ of THF was added. After workup, the product was precipitated as yellow-green crystals in $90 \%$ yield $(2.63 \mathrm{~g})$. Anal. Calcd for $\mathrm{C}_{27} \mathrm{H}_{37} \mathrm{Cl}_{4} \mathrm{~N}_{2} \mathrm{Fe}: \mathrm{C}, 55.22 ; \mathrm{H}, 6.35 ; \mathrm{N}, 4.77$. Found: C, 54.44; H, 6.31; N, 4.78.

(ii) Typical cross-coupling procedure. A Schlenk tube was charged with the iron(III)-based catalyst $(0.01 \mathrm{mmol})$, alkyl bromide $(1.00 \mathrm{mmol})$, diethyl ether $(0.8 \mathrm{~mL})$ and a stirring bar. 4-Methylphenylmagnesium bromide $(1.50 \mathrm{mmol}$, $1.07 \mathrm{~mol} / \mathrm{L}$ solution in diethyl ether) was added to this solution at $30^{\circ} \mathrm{C}$. The resulting solution turned black, and was then stirred for $20 \mathrm{~min}$ in an oil bath at $30^{\circ} \mathrm{C}$. After the reaction was quenched by adding dilute hydrochloric acid $(1 \mathrm{~mol} / \mathrm{L}$, $0.5 \mathrm{~mL})$, the mixture was extracted with ethyl acetate $(3 \times$ $4 \mathrm{~mL}$ ). The yield of the desired product is determined by GC analysis, using $n$-hexadecane as an internal standard.

\subsection{Analyses}

Carbon, hydrogen and nitrogen analyses were performed by direct combustion with a Carlo-Erba EA-1110 (Carlo-Erba Instruments, Milan, Italy). The Raman spectra were recorded on a LabRAM HR800 spectrometer (ESI-MS) data were recorded on a 6220 Accurate-Mass TOF LC/MS instrument (Agilent, Santa Clara, CA). Gas chromatographic (GC) analysis was performed on a Varian CP-3800 instrument (Varian, Palo Alto, CA) equipped with a flame ionization detector and a OV-101 capillary column $(30 \mathrm{~m} \times 0.32 \mathrm{~mm}$ I.D., $0.10 \mu \mathrm{m}$, Analytical Technology, Collegeville, PA). The oven temperature was held at $80^{\circ} \mathrm{C}$ for $2 \mathrm{~min}$, increased to $280^{\circ} \mathrm{C}$ at $10^{\circ} \mathrm{C} / \mathrm{min}$, and held for $2 \mathrm{~min}$.

\section{Results and discussion}

\subsection{Synthesis and characterization of [DIPrim] $\left[\mathrm{FeCl}_{4}\right]$}

As shown in Scheme 1, the target imidazolium salt of iron (III) [DIPrim] $\left[\mathrm{FeCl}_{4}\right]$ was easily prepared by reacting anhydrous $\mathrm{FeCl}_{3}$ with one equivalent of 1,3-bis(2,6-diisopropylphenyl)imidazolium chloride [DIPrim] $\mathrm{Cl}$ in THF at room temperature [20]. Although [DIPrim] Cl is insoluble in THF, when a THF solution of $\mathrm{FeCl}_{3}$ was added to a suspension of [DIPrim]Cl in THF, the mixed solution quickly changed 


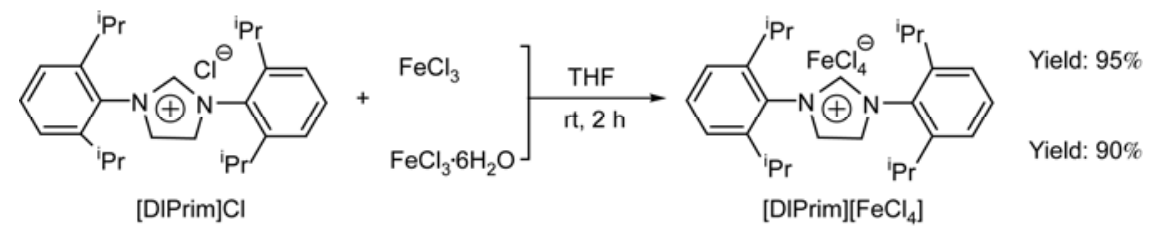

Scheme 1 Synthesis of [DIPrim] $\left[\mathrm{FeCl}_{4}\right]$.

from a suspended state to a transparent liquid. Following workup, [DIPrim] $\left[\mathrm{FeCl}_{4}\right]$ was obtained as yellow-green crystals in almost quantitative yields. Alternatively, [DIPrim] $\left[\mathrm{FeCl}_{4}\right]$ can be conveniently synthesized by a similar reaction using the inexpensive $\mathrm{FeCl}_{3} \cdot 6 \mathrm{H}_{2} \mathrm{O}$ as a starting material. However, the yield was only $90 \%$.

Although both of the ferric chlorides and the imidazolium chloride are hydrophilic, [DIPrim $]\left[\mathrm{FeCl}_{4}\right]$ is hydrophobic and air-stable in the solid state, and is therefore easy to use. This complex is also thermally stable unless the temperature is increased above $254^{\circ} \mathrm{C}$, which results in decomposition (not melting). The imidazolium chloride [DIPrim] Cl decomposed at $c a .277^{\circ} \mathrm{C}$. This complex was soluble in THF, $\mathrm{Et}_{2} \mathrm{O}$ and $\mathrm{CHCl}_{3}$, sparingly soluble in toluene, and insoluble in hexane.

[DIPrim $]\left[\mathrm{FeCl}_{4}\right]$ was initially identified by elemental analysis and further characterized by Raman spectroscopy and ESI-MS. The metal-containing anion exists as a discrete $\mathrm{FeCl}_{4}^{-}$species, which is evident in the Raman spectrum [22,23]. Figure 1 compares the Raman spectrum of [DIPrim] $\left[\mathrm{FeCl}_{4}\right]$ with that of [DIPrim]Cl. The spectrum of [DIPrim] $\left[\mathrm{FeCl}_{4}\right]$ shows a strong band at $335.956 \mathrm{~cm}^{-1}$, which is very close to the literature value of about $330 \mathrm{~cm}^{-1}$ for [BMim] $\left[\mathrm{FeCl}_{4}\right][17,22]$. This band has been previously assigned to the tetrahedral $\left[\mathrm{FeCl}_{4}\right]^{-}$species, because of the totally symmetric $\mathrm{Fe}-\mathrm{Cl}$ stretching vibration [17]. The bands observed between 900 and $1500 \mathrm{~cm}^{-1}$ are very similar to those of [DIPrim]Cl, which indicated the presence of the [DIPrim $]^{+}$ species in the obtained iron(III) complex [17]. The negative

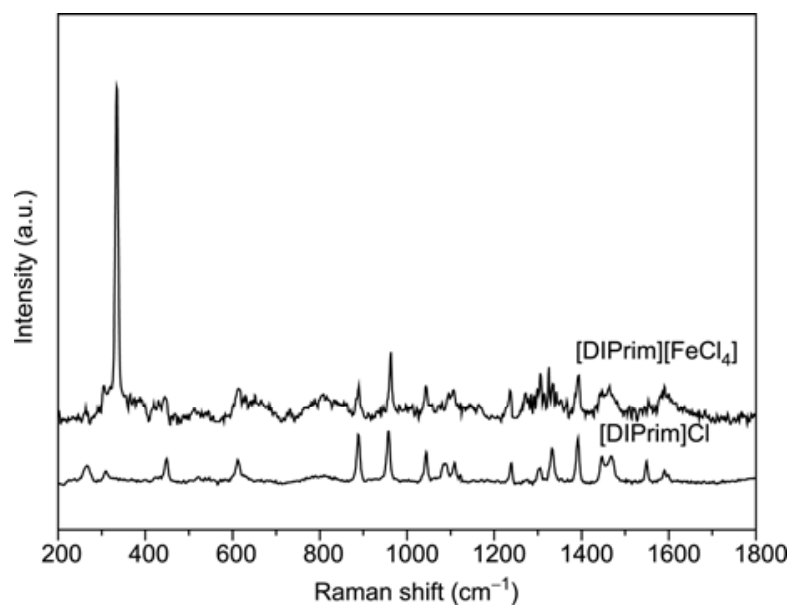

Figure 1 Raman spectra of [DIPrim] $\left[\mathrm{FeCl}_{4}\right]$ and [DIPrim]Cl. ion ESI-MS spectrum of [DIPrim] $\left[\mathrm{FeCl}_{4}\right]$ showed a peak at $\mathrm{m} / z 197.8$ with an intensity of almost $100 \%$, and a peak at $\mathrm{m} / \mathrm{z} 335.956$ with an intensity of almost $100 \%$ was observed in the positive ion ESI-MS spectrum of [DIPrim] $\left[\mathrm{FeCl}_{4}\right]$. The characteristic results clearly confirm that the obtained complex is the imidazolium salt of iron(III), [DIPrim] $\left[\mathrm{FeCl}_{4}\right]$.

\subsection{Catalysis with [DIPrim] $\left[\mathrm{FeCl}_{4}\right]$}

To assess the catalytic activity of [DIPrim] $\left[\mathrm{FeCl}_{4}\right]$ and related iron(III)-based salts, the reaction outlined in eq. (1) was selected, as it represents a prototype cross-coupling of aryl Grignard reagents with alkyl halides bearing $\beta$-hydrogens [20].

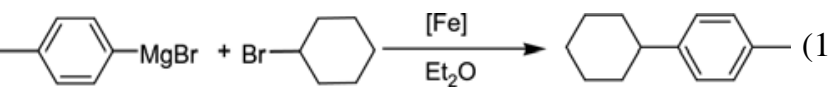

Based on the conditions developed by Gaertner for the [BMim] $\left[\mathrm{FeCl}_{4}\right]$-catalyzed cross-coupling reaction between aromatic Grignard reagents and alkyl halides [14], a set of experiments were tested to optimize the reaction conditions. Some reported conditions were found to work effectively, including the use of $\mathrm{Et}_{2} \mathrm{O}$ as solvent, the addition of the Grignard reagent in one portion, and a 1.5:1 molar ratio of the Grignard reagent and the alkyl halide. The present crosscoupling reaction can be performed successfully at elevated temperatures with reduced catalyst loading.

When the reaction was performed in the presence of [DIPrim] $\left[\mathrm{FeCl}_{4}\right]$ (amount-of-substance fraction $1 \mathrm{~mol} \%$ ) in $\mathrm{Et}_{2} \mathrm{O}$ at $30^{\circ} \mathrm{C}$ for $20 \mathrm{~min}$, the desired coupling product was obtained in almost quantitative yield (96\%) (Table 1, entry 4). Under the same conditions, the mixture of $\mathrm{FeCl}_{3}$ and [DIPrim] $\mathrm{Cl}$ in a $1: 1$ molar ratio exhibited moderate activity and provided the coupling product in $62 \%$ yield (Table 1 , entry 3). The least active was $\mathrm{FeCl}_{3}$ alone which afforded the product in a low $12 \%$ yield (Table 1 , entry 2 ). The use of [DIPrim] $\mathrm{Cl}$ alone showed no activity (Table 1, entry 1). However, increasing the reaction temperature led to a lower yield $(75 \%)$ even when the catalyst amount-of-substance fraction was increased to $2 \mathrm{~mol} \%$ (Table 1 , entry 6). Interestingly, the reaction proceeded smoothly without an inert atmosphere, and there was no obvious difference between an air atmosphere and the use of pure argon (Table 1, entry 5).

The current procedure is advantageous compared to the one catalyzed by $\left[\mathrm{BMim}^{-}\left[\mathrm{FeCl}_{4}\right][14]\right.$. The coupling is performed at $30^{\circ} \mathrm{C}$ instead of $0^{\circ} \mathrm{C}$, and the complex [DIPrim $]\left[\mathrm{FeCl}_{4}\right]$ is a solid, whereas $\left[\mathrm{BMim}^{-}\left[\mathrm{FeCl}_{4}\right]\right.$ is an oil at 
Table 1 Activities of catalytic systems based on iron(III) complexes ${ }^{\text {a) }}$

\begin{tabular}{|c|c|c|c|c|c|c|}
\hline Entry & Catalyst & $\begin{array}{c}\text { [Catalyst] } \\
(\mathrm{mol} \%)\end{array}$ & $\begin{array}{c}{[\mathrm{ArMgBr}] /[\mathrm{R}-\mathrm{Br}]} \\
\text { (molar ratio) }\end{array}$ & $\begin{array}{c}T \\
\left({ }^{\circ} \mathrm{C}\right)\end{array}$ & $t(\min )$ & Yield $^{\text {b) }}$ \\
\hline 1 & {$[$ DIPrim $] \mathrm{Cl}$} & 1 & 1.5 & 30 & 20 & 0 \\
\hline 2 & $\mathrm{FeCl}_{3}$ & 1 & 1.5 & 30 & 20 & 12 \\
\hline 3 & $\mathrm{FeCl}_{3}+[$ DIPrim $] \mathrm{Cl}$ & 1 & 1.5 & 30 & 20 & 62 \\
\hline 4 & {$[$ DIPrim $]\left[\mathrm{FeCl}_{4}\right]$} & 1 & 1.5 & 30 & 20 & 96 \\
\hline $5^{\text {c) }}$ & {$[$ DIPrim $]\left[\mathrm{FeCl}_{4}\right]$} & 1 & 1.5 & 30 & 20 & 92 \\
\hline 6 & {$[$ DIPrim $]\left[\mathrm{FeCl}_{4}\right]$} & 2 & 1.5 & Refluxing d) & 30 & 75 \\
\hline $7[14]$ & {$[\mathrm{BMim}]\left[\mathrm{FeCl}_{4}\right]$} & 5 & 1.5 & 0 & 10 & 89 \\
\hline $8[14]$ & {$[\mathrm{BMim}]\left[\mathrm{FeCl}_{4}\right]$} & 1 & 1.5 & 0 & 10 & 80 \\
\hline $9[9]$ & {$\left[\left(\mathrm{FeCl}_{3}\right)_{2}(\mathrm{TMEDA})_{3}\right]$} & 1.5 & 1.3 & $\mathrm{rt}$ & 45 & 91 \\
\hline $10[8]$ & $\mathrm{Fe}(\mathrm{acac})_{3}$ & 5 & 2.0 & Refluxing $^{\text {d) }}$ & 30 & 69 \\
\hline $11[5]$ & {$[\mathrm{FeCl}($ salen $)]$} & 5 & 2.0 & 45 & 30 & 90 \\
\hline
\end{tabular}

a) Cyclohexyl bromide (1.0 mmol), 4- $\mathrm{MeC}_{6} \mathrm{H}_{4} \mathrm{MgBr}(1.5 \mathrm{mmol}), 4-\mathrm{MeC}_{6} \mathrm{H}_{4} \mathrm{MgBr}$ was added in one portion at $30^{\circ} \mathrm{C}, \mathrm{Et}_{2} \mathrm{O}$, total volume (2.5 mL), $\mathrm{Ar}$. b) GC yield using $n$-hexadecane as internal standard. c) In air. d) External temperature $45^{\circ} \mathrm{C}$, reaction temperature $36-38^{\circ} \mathrm{C}$.

room temperature. Finally, the catalytic activity of [DIPrim $]\left[\mathrm{FeCl}_{4}\right]$ is somewhat higher than that of $[\mathrm{BMim}]\left[\mathrm{FeCl}_{4}\right]$ (Table 1, entries 7,8). This is in agreement with the general idea that a sterically bulky ligand can facilitate the reductive elimination to form the desired coupling products and regenerate the catalytic active species [21]. Furthermore, the catalytic performance of $[\mathrm{DIPrim}]\left[\mathrm{FeCl}_{4}\right]$ was compared with other related iron(III)-based catalysts reported in the literature. As seen in Table 1, amount-of-substance fractions of $3 \mathrm{~mol} \%-5 \mathrm{~mol} \%$ for iron(III) are usually required to achieve satisfactory yields of the reaction in eq. (1) $[5,8,9]$. Therefore, the present results suggest that [DIPrim] $\left[\mathrm{FeCl}_{4}\right]$ is a novel efficient catalyst for the cross-coupling reaction of aryl Grignard reagents with alkyl halides bearing $\beta$-hydrogens.

Table 2 Cross-coupling of ArMgBr with alkyl halides catalyzed by [DIPrim] $\left[\mathrm{FeCl}_{4}\right]^{\text {a) }}$

\begin{tabular}{|c|c|c|c|c|}
\hline Entry & $\operatorname{ArMgX}$ & Alkyl halide & Product & Yield (\%) ${ }^{\text {b) }}$ \\
\hline 1 & & & & 90 \\
\hline 3 & & & & $76^{c)}$ \\
\hline 4 & & & & $56^{\text {d) }}$ \\
\hline 5 & & & & $64^{\text {d) }}$ \\
\hline 6 & & & & 82 \\
\hline 7 & & & & 70 \\
\hline 9 & & $n-\mathrm{C}_{8} \mathrm{H}_{17}-\mathrm{Cl}$ & & $32^{\mathrm{e})}$ \\
\hline 10 & & $-B$ & & 82 \\
\hline 11 & & & & 72 \\
\hline 12 & & & & 89 \\
\hline 13 & & & & $43^{\text {d) }}$ \\
\hline 14 & & & & 91 \\
\hline
\end{tabular}

a) Conditions: $\operatorname{ArMgBr}(1.5 \mathrm{mmol})$, alkyl halide $(1.0 \mathrm{mmol})$, [DIPrim] $\left[\mathrm{FeCl}_{4}\right]$ (amount-of-substance fraction $\left.1.0 \%\right), \mathrm{Et}_{2} \mathrm{O}$ total volume $(2.5 \mathrm{~mL}), 30^{\circ} \mathrm{C}, 20 \mathrm{~min}$. b) Isolated yield, average of two runs. c) $60 \mathrm{~min}$. d) Catalyst (amount-of-substance fraction $2.0 \%$ ). e) Catalyst (amount-of-substance fraction $2.0 \%$ ), $45^{\circ} \mathrm{C}$. 
To study the generality of this process preliminary substrate screening was performed and the results are summarized in Table 2. Similar to cyclohexyl bromide, both cyclohexyl iodide and chloride were found to be suitable for the cross-coupling. However, the isolated yields of the desired products were slightly lower (Table 2, entries 2 and 3). The general trend for cyclohexyl halides reactivity appeared to be $\mathrm{Br}>\mathrm{I}>\mathrm{Cl}$. This is the same pattern as that previously reported with the $\mathrm{Fe}$-salen systems [5], $\mathrm{FeCl}_{3} /$ phosphine systems [12] and [BMim] $\left[\mathrm{FeCl}_{4}\right]$ [14]. Noticeably lower activity was observed if cyclohexyl bromide was replaced by its seven-ring or five-ring analogs (Table 2, entries 4 and 5 ), and yields of only $56 \%$ and $64 \%$ for the desired product were obtained even when the catalyst amount-of-substance fraction was increased to $2 \%$. Primary and open chain secondary alkyl bromides could be coupled effectively (Table 2, entries 6-8), whereas the corresponding chloride was less reactive and gave the desired product in $32 \%$ yield with a catalyst amount-of-substance fraction of $2 \%$ at an elevated temperature (Table 2, entry 9). Furthermore, the cross-coupling was also applicable to a range of Grignard reagents (Table 2, entries 1,10-14), and an electron-rich aryl Grignard reagent was found to react rapidly to give the desired product [12].

\subsection{Recyclability of [DIPrim] $\left[\mathrm{FeCl}_{4}\right]$}

Recyclability of [DIPrim] $\left[\mathrm{FeCl}_{4}\right]$ was examined by the optimized coupling of 4-methylphenylmagnesium bromide and cyclohexyl bromide with 3\% (amount-of-substance fraction) of [DIPrim $]\left[\mathrm{FeCl}_{4}\right]$. After the reaction was complete, the upper ether layer containing the product was decanted and the catalyst was left in the black sediment, which was washed twice with $0.5 \mathrm{~mL}$ of diethyl ether. The sediment containing [DIPrim] $\left[\mathrm{FeCl}_{4}\right]$ could be reused in at least four successive runs for the model reaction.

As shown in Table 3, the conversion of cyclohexyl bromide went essentially to completion. However, the isolated yield of the desired coupling product gradually decreased from $90 \%$ in the initial run to $78 \%$ after the fifth run. This

Table 3 The recyclability of $[\mathrm{DIPrim}]\left[\mathrm{FeCl}_{4}\right]$ in the cross-coupling of 4-tolylmagnesium bromide with cyclohexyl bromide ${ }^{\text {a) }}$

\begin{tabular}{cccc}
\hline Entry & Run & $\begin{array}{c}\text { Conversion of cyclohexyl } \\
\text { bromide }(\%)^{\text {b) }}\end{array}$ & ${\text { Yield }(\%)^{\mathrm{c})}}^{\text {brom }}$ \\
\hline 1 & 1 & $>99$ & 90 \\
2 & 2 & $>99$ & 89 \\
3 & 3 & $>99$ & 85 \\
4 & 4 & 96 & 80 \\
5 & 5 & 94 & 78 \\
\hline
\end{tabular}

a) Cyclohexyl bromide $(1.0 \mathrm{mmol})$, 4-tolylmagnesiumbromide $(1.5 \mathrm{mmol})$, $4-\mathrm{MeC}_{6} \mathrm{H}_{4} \mathrm{MgBr}$ was added in one portion at $30^{\circ} \mathrm{C}$, [DIPrim] $\left[\mathrm{FeCl}_{4}\right](0.03$ $\mathrm{mmol}), \mathrm{Et}_{2} \mathrm{O}(0.8 \mathrm{~mL}), 20 \mathrm{~min}, 30^{\circ} \mathrm{C}, \mathrm{Ar}$. b) $\mathrm{GC}$ yield using $n$-hexadecane internal standard. c) Isolated yield. may be attributed to the loss of the catalyst during the decanting and extraction steps.

\section{Conclusions}

In conclusion, an efficient, easy to synthesize and handle, recyclable iron(III)-based catalyst [DIPrim] $\left[\mathrm{FeCl}_{4}\right]$ was developed for the cross-coupling of aryl Grignard reagents with primary and secondary alkyl halides bearing $\beta$-hydrogens under mild conditions. Comparison between [DIPrim] $\left[\mathrm{FeCl}_{4}\right]$ and the previously reported $[\mathrm{BMim}]\left[\mathrm{FeCl}_{4}\right]$ indicates that the $N$-substituent of the imidazolium ring exerts a significant effect on the performance of the corresponding imidazolium salt of iron(III). Modification of the $\mathrm{N}$-substituent is readily accessible, and there is the potential to further fine-tune the catalytic activity of the iron(III)-containing imidazolium salt by evaluating other $N$-substituents. The detailed structure-reactivity relationship of iron(III)containing imidazolium salts and the scope of this catalyst are currently under investigation in our laboratory.

This work was supported by the National Natural Science Foundation of China (20772089), the Key Laboratory of Organic Chemistry of Jiangsu Province, and the Priority Academic Program Development of Jiangsu Higher Education Institutions.

1 de Meijere A, Diederich F. Metal-catalyzed Cross-coupling Reactions. 2nd ed. Wiley-VCH: Weinheim, 2004

2 Sherry B D, Fürstner A. The promise and challenge of iron-catalyzed cross coupling. Acc Chem Res, 2008, 41: 1500-1511

3 Czaplik W M, Mayer M, Cvengroš J, et al. Coming of age: Sustainable iron-catalyzed cross-coupling reactions. ChemSusChem, 2009, 2: 396-417

4 Martin R, Fürstner A. Cross-coupling of alkyl halides with aryl Grignard reagents catalyzed by a low-valent iron complex. Angew Chem Int Ed, 2004, 43: 3955-3957

5 Bedford R B, Bruce D W, Frost R M, et al. Iron(III) salen-type catalysts for the cross-coupling of aryl Grignards with alkyl halides bearing $\beta$-hydrogens. Chem Commum, 2004, 2822-2823

6 Martin R B, Betham M, Bruce D W, et al. Iron nanoparticles in the coupling of alkyl halides with aryl Grignard reagents. Chem Commun, 2006, 1398-1400

7 Qian X, Dawe L N, Kozak C M. Catalytic alkylation of aryl Grignard reagents by iron(III) amine-bis(phenolated) complexes. Dalton Trans, 2011, 40: 933-943

8 Nagano T, Hayashi T. Iron-catalyzed Grignard cross-coupling with alkyl halides possessing $\beta$-hydrogens. Org Lett, 2004, 6: 1297-1299

9 Cahiez G, Habiak V, Duplais C, et al. Iron-catalyzed alkylations of aromatic Grignard reagents. Angew Chem Int Ed, 2007, 46: 4364-4366

10 Nakamura M, Matsuo K, Ito S, et al. Iron-catalyzed cross-coupling of primary and secondary alkyl halides with aryl Grignard reagents. J Am Chem Soc, 2004, 126: 3686-3687

11 Bedford R B, Bruce D W, Frost R M, et al. Simple iron-amine catalysts for the cross-coupling of aryl Grignards with alkyl halides bearing $\beta$-hydrogens. Chem Commun, 2005, 4161-4163

12 Bedford R B, Betham M, Bruce D W, et al. Iron-phosphine, -phosphite, -arsine, and -carbene catalysts for the coupling of primary and secondary alkyl halides with aryl Grignard reagents. J Org Chem, 2006, 71: 1104-1110

13 Buchwald S L, Bolm C. On the role of metal contaminants in cataly- 
ses with $\mathrm{FeCl}_{3}$. Angew Chem Int Ed, 2009, 48: 5586-5587

14 Bica K, Gaertner P. An iron-containing ionic liquid as recyclable catalyst for aryl Grignard cross-coupling of alkyl halides. Org Lett, 2006, 8: 733-735

15 Alexznder M V, Khandekar A C, Samant S D. Sulfonylation reactions of aromatics using $\mathrm{FeCl}_{3}$-based ionic liquids. J Mol Catal A, 2004, 223: 75-83

16 Nguyen M D, Nguyen L V, Jeon E H, et al. Fe-containing ionic liquids as catalysts for the dimerization of bicycle[2.2.1]hepta-2,5-diene. J Catal, 2008, 258: 5-13

17 Wang H, Yan R Y, Li Z X, et al. Fe-containing magnetic ionic liquid as an effective catalyst for the glycolysis of poly(ethylene terephthalate). Catal Commun, 2010, 11: 763-767

18 Pârvulescu V I, Hardacre C. Catalysis in ionic liquids. Chem Rev, 2007, 107: 2615-2665
19 Šebesta R, Kmentová I, Toma Š. Catalysts with ionic tag and their use in ionic liquids. Green Chem, 2008, 10: 484-496

20 Gao H H, Yan C H, Tao X P, et al. Synthesis of anionic iron(II) complex bearing an $\mathrm{N}$-heterocyclic carbene ligand and its catalysis for aryl Grignard cross-coupling of alkyl halides. Organometallics, 2010, 29: 4189-4192

21 Huang J K, Nolan S P. Efficient cross-coupling of aryl chlorides with aryl Grignard reagents (Kumada reaction) mediated by a palladium/ imidazolium chloride system. J Am Chem Soc, 1999, 121: 9889-9890

22 Sitze M S, Schreiter E R, Patterson E V, et al. Ionic liquids based on $\mathrm{FeCl}_{3}$ and $\mathrm{FeCl}_{2}$. Raman scattering and ab initio calculation. Inorg Chem, 2001, 40: 2298-2304

23 Del Sesto R E, McCleskey T M, Burrel A K, et al. Structure and magnetic behavior of transition metal based ionic liquids. Chem Commun, 2008, 447-449

Open Access This article is distributed under the terms of the Creative Commons Attribution License which permits any use, distribution, and reproduction in any medium, provided the original author(s) and source are credited. 